\title{
ESTUDO DA RELAÇÃO DE CONFIANÇA EM PROGRAMA DE FOMENTO FLORESTAL DE INDÚSTRIA DE CELULOSE NA VISÃO DOS PRODUTORES RURAIS ${ }^{1}$
}

\author{
Fabiano Luiz da Silva², James Jackson Griffith ${ }^{3}$, Laércio Antônio Gonçalves Jacovine ${ }^{3}$, José Horta \\ Valadares ${ }^{4}$, Marília Aparecida Silva Fernandes ${ }^{5}$ e Elaine Cristina Gomes da Silva ${ }^{2}$
}

\begin{abstract}
RESUMO - Este estudo analisou os fatores que contribuem para a relação de confiança no Programa de Fomento Florestal de indústria de celulose e produtores rurais fomentados em Minas Gerais. Foram aplicados 141 questionários a produtores rurais fomentados, em 32 municípios de sete microrregiões mineiras. A amostragem foi aleatória estratificada, sendo os critérios: a) Produtor Fomentado com Contrato Finalizado (PFCF) composto por produtores que possuíam pelo menos um contrato encerrado com a indústria de celulose; e b) Produtor Fomentado com Contrato em Andamento (PFCA) composto por produtores que não haviam finalizado nenhum contrato de fomento com a indústria de celulose. Os produtores fomentados realizam contrato de fomento florestal para apenas a primeira rotação. Assim, legalmente possuem a obrigatoriedade de entrega de $97 \%$ da madeira do primeiro ciclo da floresta. Entretanto, referente ao segundo ciclo não contratado da floresta, $18 \%$ dos produtores fomentados disseram ter interesse na comercialização dessa madeira com a empresa, indiferente de variações em preços de produtos concorrentes, como o carvão vegetal. Acredita-se que, não havendo oscilações significativas nesses mercados concorrentes, $50 \%$ dos fomentados devem comercializar o segundo corte com a empresa fomentadora. Atualmente, em $98,4 \%$ dos contratos realizados com produtores rurais fomentados há cumprimento de ambas as partes nos acordos firmados. A confiança e confiabilidade no relacionamento entre indústria de celulose e fomentados foram confirmadas, mas existem alguns fatores que contribuem para a possível desconfiança no fomento florestal, como: o sistema de medida da madeira, o custo de transporte e a ausência de política de preços que favorecem o entendimento dos produtores fomentados.
\end{abstract}

Palavras-chave: Fomento florestal, confiança e indústria de celulose.

\section{STUDY OF TRUST RELATIONSHIPS IN PRIVATE WOODLOT PRODUCTION FOR A CELLULOSE INDUSTRY FROM THE POINT OF VIEW OF RURAL PRODUCERS}

\begin{abstract}
This study analyzed factors that contribute to relations of trust within a private woodlot producer program managed by a cellulose industry in Minas Gerais state. One hundred and forty one questionnaires were completed by interviewing small woodlot rural producers that participate in 32 municipalities within 7 of the state's microregions. The sampling was performed by random stratification according to the following criteria: a) Woodlot Producers with Completed Contract (PFCF) who have finished at least one contract with the cellulose firm and b) Woodlot Producers with Contract in Progress (PFCA) who have not yet completed a contract. In general, the program's woodlot producers will sign contracts only for the first forest cut. This
\end{abstract}

\footnotetext{
${ }^{1}$ Recebido em 25.09.2007 e aceito para publicação em 29.05.2009.

${ }^{2}$ Programa de Pós-Graduação em Ciência Florestal da Universidade Federal de Viçosa (UFV). E-mail: <fabianocoop@ yahoo.com.br>.

${ }^{3}$ Departamento de Engenharia Florestal da UFV. E-mail: <griffith@ufv.br>.

${ }^{4}$ Departamento de Economia Rural da UFV. E-mail: <jhorta@ufv.br>.

${ }^{5}$ Graduação em Gestão de Cooperativas da UFV. E-mail: <mariliapaf@ yahoo.com.br>.
} 
means that they are obligated to deliver to the company $97 \%$ of the wood from the first cycle of production. However, for the second cycle, $18 \%$ of those interviewed showed interest in selling their wood to the cellulose firm regardless of whatever price variations might occur for competing forest markets such as for charcoal. If no significant fluctuations occur in these competing markets it is possible that as many as $50 \%$ of woodlot producers might sell their second cut to the cellulose firm. Once rural producers sign on to the program, 98.4\% of them complete their contractual obligations. Trust and trustworthiness were confirmed as existing in relationships between the cellulose firm and woodlot producers. However, there are some factors in the woodlot program that contribute to mistrust, including the wood measurement system, transport costs and the absence of a pricing policy easily understood by woodlot producers.

Keywords: Private woodlot programs, trust and cellulose industry.

\section{INTRODUÇÃO}

O Brasil tem sido um dos países onde investimentos significativos no setor florestal estão acontecendo. Porém, um dos grandes gargalos do desenvolvimento das indústrias de base florestal, seja para celulose, serraria ou carvão vegetal, está no seu suprimento de matéria-prima, ou seja, a madeira.

De acordo com Soares (2006), o fomento florestal é uma das estratégias das empresas para garantir seu suprimento de matéria-prima. O interesse das indústrias é reduzir a imobilização de recursos em terras e capital. Assim, o fomento florestal é importante para o setor, além de estar contribuindo para o desenvolvimento local (VALVERDE, 2003).

Nos contratos de fomento das empresas florestais, especificamente celulose e papel, são repassados aos produtores de mudas, fertilizantes, defensivos, recursos financeiros e assistência técnica (OLIVEIRA, 2003).

A principal dúvida sobre investimentos em programas de fomento florestal é: Podemos confiar a produtores fomentados o suprimento de madeira? Entre as alternativas para responder a essa questão, uma está em uma abordagem que possa refletir sobre os elementos que contribuem para a relação de confiança entre produtores e empresas fomentadoras.

A corrente teórica denominada Nova Economia Institucional (NEI) possui como um dos seus elementos de análise a confiança. A NEI propõe uma discussão a respeito da análise do ambiente econômico, colocando o papel da estrutura e da organização política e social na determinação dos acontecimentos econômicos (ZYLBERSZTAJN, 2005).

R. Árvore, Viçosa-MG, v.33, n.4, p.723-732, 2009
Os custos antes e depois da formulação e execução dos contratos são abordados na NEI. Também, realizamse reflexões sobre o papel das instituições econômicas e sociais como uma forma de resolver o problema da cooperação entre os indivíduos. A confiança é uma das variáveis que integram a Nova Economia Institucional, por contribuir na análise e discussão sobre as relações contratuais.

Este estudo visa identificar elementos básicos para análise da relação de confiança, via contratos de fomento florestal para produção de eucalipto para celulose. O programa foco dessa pesquisa é o fomento da Celulose Nipo-Brasileira (CENIBRA) localizada na Mesorregião do Vale do Rio Doce, em Minas Gerais, Brasil.

\section{MATERIAL E MÉTODOS}

\subsection{Descrição da área de estudo}

A Mesorregião do Vale do Rio Doce é composta por 102 municípios e sete microrregiões, definidas como Aimorés, Caratinga, Governador Valadares, Guanhães, Ipatinga, Mantena e Peçanha.

O fomento florestal dessa indústria de celulose se divide em seis grandes regiões localizadas nas microrregiões de Guanhães, Ipatinga, Caratinga, Governador Valadares e Peçanha.

Os critérios de definição das regionais do fomento são estabelecidos segundo a área plantada por município. Atualmente, são 68 municípios abrangidos pelo programa de fomento florestal da CENIBRA.

No momento da pesquisa, eram 733 produtores fomentados em todas as regionais de abrangência do programa da empresa de base florestal. 


\subsection{Fases metodológicas}

\subsubsection{Conhecimento da realidade do fomento}

Durante o início de 2006, nos meses de fevereiro e março foram realizadas cinco reuniões com técnicos da empresa de base florestal, a fim de conhecer o programa de fomento na visão da empresa. Por meio dessas reuniões, foram identificados os anseios e dificuldades da empresa sobre o programa de fomento e as respectivas estratégias, adotadas para estabelecimento da relação de confiança entre os atores (empresa e produtores).

\subsubsection{Entrevista pré-elaboração de questionário}

No mês de abril de 2006 foram realizadas entrevistas de pré-elaboração do questionário com o objetivo de identificar elementos para construção da pesquisa de campo. Para tanto, foram entrevistados produtores de três das regionais do fomento florestal da empresa.

Nessa etapa, o objetivo foi conhecer a visão dos produtores florestais sobre o programa de fomento, suas principais dificuldades, seu histórico profissional, impacto da renda com o fomento, a capacidade de organização dos produtores e quais eram as perspectivas no relacionamento com a indústria de celulose.

\subsubsection{Elaboração e discussão de questões levantadas na pesquisa}

Realizaram-se duas reuniões com professores das áreas de engenharia florestal e economia/extensão rural da Universidade Federal de Viçosa, usando informações levantadas nas entrevistas pré-elaboração. Foi proposto um modelo de questionário aplicado aos fomentados da indústria de celulose.

O questionário foi elaborado com questões abertas, fechadas e semiabertas. Estas foram utilizadas para melhor ajuizar a confiança entre o produtor e a empresa florestal.

Para validação e fechamento das informações coletadas no campo, foi realizada uma reunião da equipe de pesquisa com técnicos coordenadores da área de fomento e meio ambiente da indústria de celulose. Nessa reunião foram incorporadas novas questões para a análise da relação de confiança entre indústria de celulose e produtores rurais fomentados.

\subsubsection{Aplicação de pré-teste}

Durante os dias 23, 24 e 25 de abril de 2006, foram realizadas oito entrevistas com produtores fomentados da indústria de celulose, no intuito de verificar a aplicabilidade do questionário, o entendimento das questões pelos entrevistados e possíveis correções para facilitar a coleta das informações.

\subsubsection{Amostragem e estratificação}

Por meio do banco de dados, os produtores fomentados pela empresa foram agrupados em duas classes, a saber:

Classe 1: Produtor Fomentado com Contrato Finalizado (PFCF) - composto por produtores que possuíam pelo menos um contrato encerrado com a empresa. Por meio dessa classificação, foi possível selecionar os produtores que tiveram experiência com a empresa (em pelos menos um contrato) desde a assinatura, significando que houve recebimento dos insumos, plantio, manutenção, corte, colheita, transporte, entrega da madeira e seu recebimento.

Classe 2: Produtor Fomentado com Contrato em Andamento (PFCA) - Constituída por produtores que não finalizaram nenhum contrato com a empresa fomentadora. Por meio dessa classificação, foi possível selecionar os produtores que ainda não tinham experiência com a empresa em todas as etapas acordadas no contrato de fomento florestal.

\subsubsection{Processamento dos dados}

Os dados foram tabulados na planilha eletrônica do Excel®, e, posteriormente, realizou-se o processamento das informações.

\section{RESULTADOS E DISCUSSÕES}

\subsection{Os contratos de fomento florestal para celulose}

Os modelos de contratos de fomento praticados pela empresa assumem duas modalidades: contrato de fomento comercial e o contrato de fomento convencional. No contrato de fomento comercial, a indústria de celulose é responsável pelo plantio e o produtor arca com todos os custos de implantação. Já no contrato de fomento convencional a empresa fornece os insumos subsidiados, e o produtor é responsável pela realização das atividades silviculturais.

A distribuição por regional dos PFCA e PFCF é representada na Figura 1. Pode-se afirmar que existe distribuição próxima nos percentuais das regiões entre as duas categorias de produtores, demonstrando uniformidade na situação contratual entre os fomentados.

R. Árvore, Viçosa-MG, v.33, n.4, p.723-732, 2009 


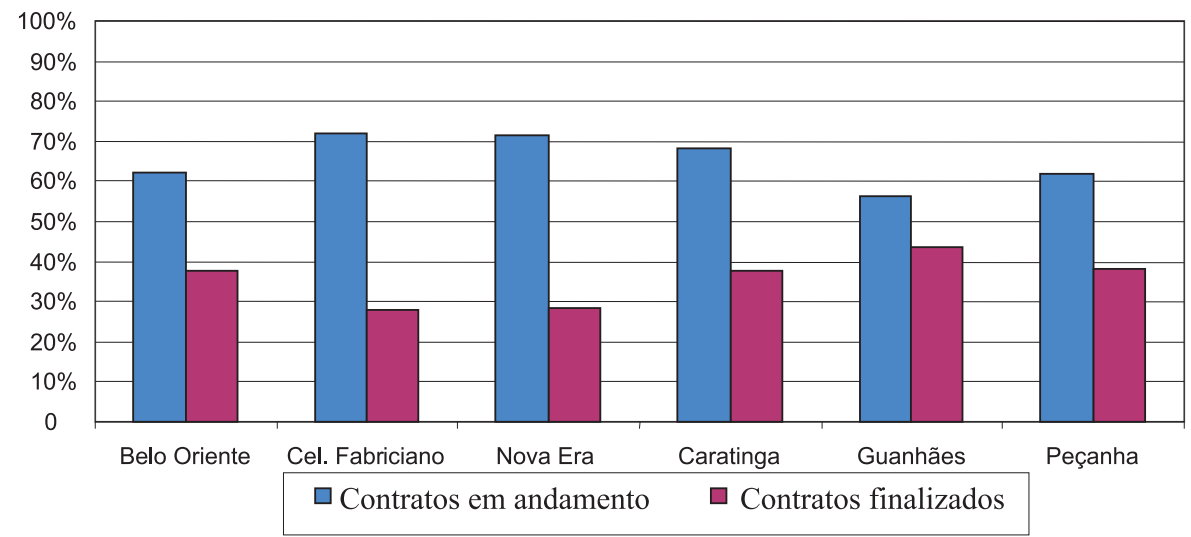

Figura 1 - Contratos finalizados e em andamento por regional.

Figure 1 -Completed contracts and contracts in progress by region.

\subsection{Expectativas, vantagens e estímulos para adesão ao fomento florestal}

Na Tabela 1 são apresentadas as principais expectativas dos produtores ao participar do programa de fomento, são elas: retorno financeiro (receita e despesas), renda no longo prazo (poupança), diversificação de renda (outra renda), recuperação de áreas degradadas, aprendizagem das técnicas para silvicultura e outras.

O retorno financeiro (Tabela 1) teve o maior número de citações entre os produtores (71\% média geral), não havendo variação significativa nos grupos PFCA e PFCF. Nos Produtores Fomentados com Contrato Finalizado, a renda de longo prazo toma dimensão maior em relação à classe dos PFCA, devido à percepção do produtor de que o plantio florestal garante renda no longo prazo, caracterizando-se como uma poupança.

Os itens referentes à renda (retorno financeiro e renda de longo prazo) são as expectativas mais destacadas pelos produtores fomentados, ou seja, o lucro com a produção da floresta tem significativo peso na expectativa e, consequentemente, na decisão de assinatura de um contrato de fomento florestal.

Para os PFCA, era de se esperar que houvesse expectativa para aprender as técnicas para a silvicultura, porque são novos no ramo do reflorestamento. Entretanto, o valor baixo (4\%) atribuído a esse item parece indicar que outras expectativas ao plantar eucalipto são mais importantes para eles.

A Tabela 2 contém as principais vantagens do programa de fomento na visão dos produtores florestais fomentados.

Para 23\% dos PFCF, os insumos oferecidos pelo programa de fomento representam a principal vantagem do programa de fomento florestal. Tal fato acontece devido à falta de capitalização do produtor rural para aumentar ou iniciar um negócio florestal em sua propriedade.

Tabela 1 - Expectativa dos produtores ao participar do fomento florestal Table 1 - Producer expectations upon joining the private woodlot program

\begin{tabular}{|c|c|c|c|c|c|c|}
\hline \multirow[t]{2}{*}{ Item } & \multicolumn{2}{|c|}{ PFCA } & \multicolumn{2}{|c|}{ PFCF } & \multicolumn{2}{|c|}{ Média Geral } \\
\hline & No. & $\%$ & No. & $\%$ & No. & $\%$ \\
\hline Retorno financeiro (receita e despesas) & 60 & 71 & 40 & 70 & 100 & 71 \\
\hline Renda a longo prazo (poupança) & 6 & 7 & 9 & 16 & 15 & 11 \\
\hline Recuperação áreas degradadas & 6 & 7 & 5 & 9 & 11 & 8 \\
\hline Diversificação da renda & 7 & 8 & 2 & 3 & 9 & 6 \\
\hline Aprendizagem das técnicas para silvicultura & 3 & 4 & 1 & 2 & 4 & 3 \\
\hline Outras expectativas & 2 & 3 & 0 & 0 & 2 & 1 \\
\hline Total & 84 & 100 & 57 & 100 & 141 & 100 \\
\hline
\end{tabular}

PFCA = Produtor Fomentado com Contrato em Andamento.

$\mathrm{PFCF}=$ Produtor Fomentado com Contrato Finalizado

R. Árvore, Viçosa-MG, v.33, n.4, p.723-732, 2009 
Tabela 2 - Principal vantagem do programa de fomento na visão dos fomentados Table 2 - Principal advantage of the woodlot program as viewed by its members

\begin{tabular}{|c|c|c|c|c|c|c|}
\hline \multirow[t]{2}{*}{ Item } & \multicolumn{2}{|c|}{ PFCA } & \multicolumn{2}{|c|}{ PFCF } & \multicolumn{2}{|c|}{ Média Geral } \\
\hline & No. & $\%$ & No. & $\%$ & No. & $\%$ \\
\hline $\begin{array}{l}\text { Insumos e financiamento oferecidos pelo } \\
\text { programa de fomento }\end{array}$ & 29 & 35 & 13 & 23 & 42 & 30 \\
\hline Retorno financeiro & 20 & 24 & 9 & 16 & 29 & 21 \\
\hline Sustentabilidade do agronegócio florestal & 11 & 13 & 12 & 21 & 23 & 16 \\
\hline Assistência técnica da empresa & 7 & 8 & 3 & 5 & 10 & 7 \\
\hline Baixo custo de mão de obra na atividade & 2 & 2 & 1 & 2 & 3 & 2 \\
\hline $\begin{array}{l}\text { Outras vantagens (comercializar a madeira } \\
\text { em outros mercados e recuperar áreas degradadas) }\end{array}$ & 9 & 11 & 12 & 21 & 21 & 15 \\
\hline Não opinou & 6 & 7 & 7 & 12 & 13 & 10 \\
\hline Total & 84 & 100 & 57 & 100 & 141 & 100 \\
\hline
\end{tabular}

A sustentabilidade do agronegócio florestal foi o segundo destaque (21\%) entre os PFCF, pois os produtores buscam alternativas de negócios que sejam viáveis economicamente e que demonstrem segurança no investimento.

Essa segurança de investimento proporcionado pelo fomento florestal contribui para redução da aversão ao risco vindo de produtores, o que é comum em atividades de longo prazo, sujeitas também a influências climáticas e outras.

Quanto aos principais estímulos para adesão ao fomento (Tabela 3), o item retorno financeiro obteve o percentual de $43 \%$ entre os PFCA. Já na classe PFCF foi de $34 \%$, pois o ganho financeiro do fomento é baixo comparado, na visão dos produtores, com outros negócios de madeira, a exemplo da produção de carvão vegetal ou da venda de madeira para escoramento.

O ganho financeiro não foi o único fator gerador de expectativa, vantagem e estímulo dos produtores fomentados para adesão ao programa. Os insumos oferecidos (média geral 18\%) e recuperação de áreas degradadas (média geral 11\%), com consequente valorização da propriedade, influenciam também a decisão dos produtos na relação de confiança com a empresa e a assinatura de um contrato de fomento florestal.

Além de a capacidade do programa de fomento contribuir com a propriedade e desenvolvimento local, buscou-se identificar os seus principais pontos negativos na visão dos produtores (Tabela 4).

Dos pontos negativos relacionados na Tabela 4, em média geral, $77 \%$ dos produtores concordam com eles, sendo $76 \%$ para PFCA e $78 \%$ para PFCF.

Na média geral, 33\% dos produtores fomentados desconhecem pontos negativos do programa, porém os $67 \%$ restantes citaram: preço da madeira, custo de transporte e o sistema de medida da madeira.

Esses pontos negativos são fatores que influenciam os produtores a desconfiarem do programa de fomento florestal, e os principais questionamentos expostos pelos produtores foram:

- Relativo ao preço - Já que a celulose é um produto para exportação, e os ganhos nessa transação econômica são significativos, porque a madeira de fomento não acompanha a variação dos preços de exportação da celulose?

Tabela 3 - Pincipais estímulos aos produtores para adesão ao programa de fomento Table 3 -Principal incentives for producers who join the woodlot program

\begin{tabular}{|c|c|c|c|c|c|c|}
\hline \multirow[t]{2}{*}{ Item } & \multicolumn{2}{|c|}{ PFCA } & \multicolumn{2}{|c|}{ PFCF } & \multicolumn{2}{|c|}{ Média Geral } \\
\hline & No. & $\%$ & No. & $\%$ & No. & $\%$ \\
\hline Retorno financeiro (receita e despesas) & 36 & 43 & 19 & 34 & 55 & 39 \\
\hline Insumos e financiamento oferecidos pelo programa & 13 & 15 & 12 & 21 & 25 & 18 \\
\hline Recuperação de áreas degradadas. & 9 & 11 & 7 & 12 & 16 & 11 \\
\hline Amigos proprietários & 9 & 11 & 7 & 12 & 16 & 11 \\
\hline Outros estímulos & 17 & 20 & 12 & 21 & 29 & 21 \\
\hline Total & 84 & 100 & 57 & 100 & 141 & 100 \\
\hline
\end{tabular}


Tabela 4 - Pontos negativos do programa de fomento na opinião dos fomentados

Table 4 - Negative points about the woodlot program according to program members

\begin{tabular}{|c|c|c|c|c|c|c|}
\hline \multirow[t]{2}{*}{ Item } & \multicolumn{2}{|c|}{ PFCA } & \multicolumn{2}{|c|}{ PFCF } & \multicolumn{2}{|c|}{ Média Geral } \\
\hline & No. & $\%$ & No. & $\%$ & No. & $\%$ \\
\hline Desconhecem pontos negativos do fomento & 28 & 33 & 19 & 33 & 47 & 33 \\
\hline Discordam do preço da madeira & 22 & 26 & 14 & 25 & 36 & 26 \\
\hline Insatisfeitos com o custo de transporte & 11 & 13 & 8 & 14 & 19 & 13 \\
\hline $\begin{array}{l}\text { Citaram pessoas que pensam que eucalipto seca } \\
\text { a água e estraga o terreno }\end{array}$ & 11 & 13 & 7 & 12 & 18 & 13 \\
\hline Discordam do sistema de medida da madeira & 9 & 11 & 8 & 14 & 17 & 12 \\
\hline Outros pontos negativos & 3 & 4 & 1 & 2 & 4 & 3 \\
\hline Total & 84 & 100 & 57 & 100 & 141 & 100 \\
\hline
\end{tabular}

- Relativo ao custo de transporte - Porque os produtores mais distantes são beneficiados com elevação do preço da madeira para custeio do transporte? Com essa política, os produtores mais próximos não são penalizados?

Relativo a produtores que não participam do fomento - Porque a empresa não constrói uma estratégia para erradicar de vez as dúvidas relativas aos impactos dos plantios florestais e agregação de novos produtores na atividade florestal?

- Relativo ao sistema de medida - Para não gerar dúvidas sobre sua eficácia, porque a empresa não definiu um padrão de medida de madeira que seja de fácil entendimento pelos produtores?

\subsection{A confiança dos produtores fomentados}

Diversos níveis de desenvolvimento estão associados a diferentes níveis de confiança, e a desconfiança também exerce influência sobre os grupos sociais (PUTNAM, 1993).

De acordo com Hardin (2001), a confiança (trust) pode ser entendida como expectativa de comportamento (confiabilidade), ou seja, conhecimento, ações e comportamentos são bases para o estabelecimento de uma relação de confiança, de pessoa para pessoa, organização para pessoas e organização para organização.

O sentimento de confiança é outra forma de entendimento na visão de Hardin (2001), pois neste o "trust" se inicia desde a relação de filho com a mãe, por exemplo. Pode também ser um sentimento em relação a outras pessoas.
Segundo esse mesmo autor, as pessoas possuem motivações para confiar e cooperar, e tais ações podem trazer a confiança.

Também existem riscos, pois, à medida que ocorrem as transações entre atores, vão sendo gerados fatores que podem reduzir as relações, sejam essas sociais ou econômicas (HARDIN, 2001).

Por meio do banco de dados da indústria de celulose, foi identificado o índice de $98,4 \%$ de produtores rurais fomentados que cumpriram, ou estão cumprindo, com todos os direitos e deveres acordados no contrato.

A respeito da confiabilidade no cumprimento do contrato por parte da indústria de celulose, foi solicitado aos produtores que opinassem sobre as etapas da relação contratual. O resultado está expresso na Tabela 5.

Todos os itens abordados (Tabela 5) demonstram índices favoráveis à relação entre os produtores fomentados e a indústria de celulose.

O sistema de recebimento da madeira (23\%) e o valor pago pela madeira proposto no contrato $(21 \%)$ se destacam como pouco confiável, o que pode ser explicado pela falta de entendimento do sistema de medida da madeira e pelos preços ditados pelo mercado.

Um destaque da afirmação "pouco confiável”, referente ao recebimento da madeira $(23 \%)$, teve como comentário central a dificuldade no entendimento do sistema adotado para medir a madeira e a utilização de dois métodos diferentes (pátio e fábrica). Isso gera desconfiança sobre a eficácia dos sistemas.

Os produtores relataram como ponto positivo o fato de não haver oscilações bruscas no preço pago pela madeira $(70 \%)$ para celulose dentro da mesorregião do Vale do Rio Doce. 
Tabela 5 - A confiabilidade atribuída pelo fomentado às etapas do contrato

Table 5 - Trustworthiness rating by program members for each phase of the contract

\begin{tabular}{|c|c|c|c|c|c|c|}
\hline \multirow[t]{2}{*}{ Item } & \multicolumn{2}{|c|}{ Pouco confiável } & \multicolumn{2}{|c|}{ Confiável } & \multicolumn{2}{|c|}{ Muito confiável } \\
\hline & No. & $\%$ & No. & $\%$ & No. & $\%$ \\
\hline Pagamento da madeira & 2 & 2 & 45 & 39 & 69 & 59 \\
\hline Fornecimento de insumos do programa de fomento & 4 & 3 & 73 & 54 & 57 & 43 \\
\hline Assistência técnica da empresa & 10 & 7 & 84 & 63 & 39 & 30 \\
\hline Financiamento dentro do programa de fomento & 12 & 12 & 62 & 64 & 23 & 24 \\
\hline Entrega da madeira na empresa (pátio ou fábrica) & 25 & 23 & 69 & 63 & 15 & 14 \\
\hline Trabalho do Instituto Estadual de Florestas - IEF & 16 & 12 & 98 & 74 & 18 & 14 \\
\hline Valor pago pela madeira proposto no contrato & 29 & 21 & 96 & 70 & 13 & 9 \\
\hline
\end{tabular}

O pagamento da madeira por parte da empresa apresentou índice de alta confiabilidade (59\%), sendo apontado como grande vantagem no contrato de fomento florestal. Essa percepção é influenciada pelo contraste de experiências negativas na comercialização de outros produtos da propriedade do fomentado da região em estudo.

A entrega na propriedade dos insumos acordados no programa de fomento obteve índice confiável (54\%) e muito confiável (43\%), demonstrando confiabilidade no cumprimento por parte da empresa.

Ao serem questionados, os fomentados demonstraram sua confiança em relação à indústria de celulose, baseando sua resposta em experiências de vida, número de vezes que relacionou com pessoas da empresa, pontualidade na entrega dos insumos acordados e nível de assistência oferecida para condução do plantio. Desses, $96 \%$ disseram confiar, e $4 \%$ apenas demonstram não confiar. Esses dados estão apresentados na Figura 2.
Procurou-se, neste trabalho, levantar quais motivos poderiam contribuir para que os produtores florestais fomentados não confiassem na empresa fomentadora (Tabela 6).

A porcentagem dos que não opinou foi de $40 \%$, índice que se manteve próximo nas classes de PFCA e PFCF. Também se destacou o item "não cumprir o preço combinado" (33\%) e "não pagar" (16\%). Essas respostas se fundamentam na expectativa de o preço a ser recebido no futuro pela madeira ser realmente o praticado pelo mercado de madeira para celulose.

Apesar de a questão econômica ser predominante, os produtores levam também em consideração os subsídios firmados pelo contrato, argumentando que eles contribuem para aumentar a confiança na relação com a empresa fomentadora.

De acordo com Williamson (1985), o número e qualidade das transações influenciam a decisão do produtor de continuar ou diminuir sua participação nas relações contratuais.

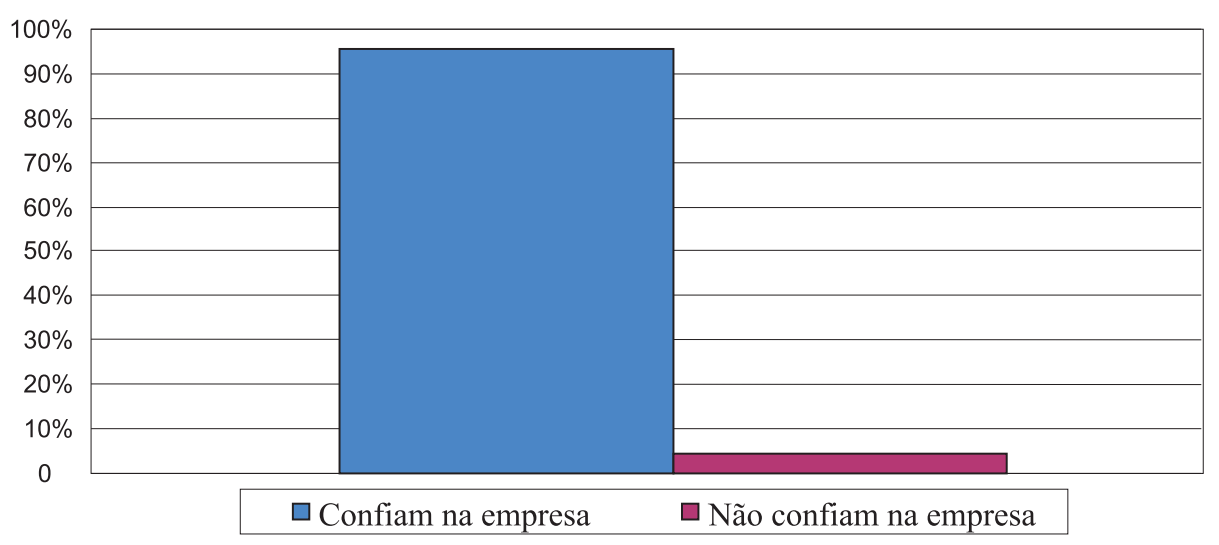

Figura 2 - A confiança dos produtores em relação à empresa.

Figure 2-Producer trust in relation to the cellulose firm. 
Tabela 6 - Razões citadas pelos produtores como motivos que podem levar à falta de confiabilidade na empresa Table 6 - Reasons cited by producers as possible motives for future mistrust in the company

\begin{tabular}{|c|c|c|c|c|c|c|}
\hline \multirow[t]{2}{*}{ Item } & \multicolumn{2}{|c|}{ PFCA } & \multicolumn{2}{|c|}{ PFCF } & \multicolumn{2}{|c|}{ Média Geral } \\
\hline & No. & $\%$ & No. & $\%$ & No. & $\%$ \\
\hline Não opinou & 31 & 37 & 25 & 44 & 56 & 40 \\
\hline Não cumprir o preço combinado & 30 & 36 & 16 & 28 & 46 & 33 \\
\hline Não pagar & 13 & 16 & 9 & 16 & 22 & 16 \\
\hline Ter problemas ao entregar a madeira & 6 & 7 & 3 & 5 & 9 & 6 \\
\hline Atrasar o pagamento & 2 & 2 & 3 & 5 & 5 & 3 \\
\hline Tomar prejuízo & 2 & 2 & 1 & 2 & 3 & 2 \\
\hline Total & 84 & 100 & 57 & 100 & 141 & 100 \\
\hline
\end{tabular}

O índice de $6 \%$ foi relativo ao problema de entrega da madeira à empresa, sempre acompanhado da dúvida dos produtores sobre o atual sistema de medida adotado para a mensuração da madeira dos fomentados.

Atualmente, o modelo de contrato adotado no programa de fomento define a obrigatoriedade da entrega da madeira somente na primeira rotação, ficando, a partir de então, o produtor livre para comercializar e utilizar para outros usos a sua floresta.

O interesse dos fomentados em entregar o segundo corte (livre do contrato) está expresso na Tabela 7.

Na média geral, $61 \%$ dos pesquisados disseram que os produtores não possuíam no momento interesse em entregar a madeira da brotação para a empresa fomentadora, e 33\% afirmaram que sim.
Os produtores se interessam pelo programa de fomento, principalmente, como meio de capitalização na atividade florestal, pois possuem interesse em utilizar a madeira para outros fins. Dessa forma, desejando ter liberdade de negociação de sua madeira no mercado após a finalização do contrato.

Nas questões abordadas, procurou-se indagar os produtores sobre as razões que os levariam a entregar ou nãoo segundo corte da madeira para a empresa fomentadora. As respostas são apresentadas na Tabela 8 .

Dos produtores que disseram depender do preço da madeira para vender para a indústria de celulose, alguns compararam os outros fins dados à madeira para servirem de parâmetro de decisão de venda. Ou seja, o interesse em comercializar o segundo corte com a indústria de celulose será influenciado pela rentabilidade de outros mercados.

Tabela 7 - Interesse dos produtores na comercialização do segundo corte da floresta com a empresa de celulose Table 7 -Producer interest in selling the second forest cut to the cellulose firm

\begin{tabular}{|c|c|c|c|c|c|c|}
\hline \multirow[t]{2}{*}{ Item } & \multicolumn{2}{|c|}{ PFCA } & \multicolumn{2}{|c|}{ PFCF } & \multicolumn{2}{|c|}{ Média Geral } \\
\hline & No. & $\%$ & No. & $\%$ & No. & $\%$ \\
\hline Sim & 28 & 33 & 18 & 31 & 46 & 33 \\
\hline Não & 52 & 62 & 34 & 60 & 86 & 61 \\
\hline Não opinou & 4 & 5 & 5 & 9 & 9 & 6 \\
\hline Total & 84 & 100 & 57 & 100 & 141 & 100 \\
\hline
\end{tabular}

Tabela 8 - Razões dos produtores para entregar ou não o segundo corte da madeira para a empresa

Table 8 -Reasons given by producers for selling or not selling the second forest cut to the cellulose firm

\begin{tabular}{|c|c|c|c|c|c|c|}
\hline \multirow[t]{2}{*}{ Item } & \multicolumn{2}{|c|}{ PFCA } & \multicolumn{2}{|c|}{$\mathrm{PFCF}$} & \multicolumn{2}{|c|}{ Média Geral } \\
\hline & No. & $\%$ & No. & $\%$ & No. & $\%$ \\
\hline Venderá dependendo do preço da madeira & 29 & 34 & 17 & 30 & 46 & 32 \\
\hline Venderá para escoramento & 4 & 5 & 1 & 2 & 5 & 3 \\
\hline Venderá para cerâmica, padaria, etc. & 3 & 4 & 7 & 12 & 10 & 7 \\
\hline Venderá para a empresa & 14 & 17 & 11 & 19 & 25 & 18 \\
\hline Produzirá carvão & 28 & 33 & 18 & 32 & 46 & 32 \\
\hline Não opinou & 6 & 7 & 3 & 5 & 9 & 8 \\
\hline Total & 84 & 100 & 57 & 100 & 141 & 100 \\
\hline
\end{tabular}

R. Árvore, Viçosa-MG, v.33, n.4, p.723-732, 2009 
Em média, $18 \%$ dos produtores, com base no mercado atual, afirmaram estarem dispostos a vender sua madeira de segundo corte para a empresa fomentadora.

Analisando o perfil desses produtores, identificase que o tamanho médio de suas áreas plantadas corresponde a 31,6 ha, o número médio de contratos são próximos a 3 e a área de maior concentração desses produtores está nas regiões de Belo Oriente, Caratinga e Coronel Fabriciano.

Considera-se que o índice de $18 \%$ é um bom percentual, pois na região existe forte concorrência pela compra de madeira pelas empresas consumidoras de carvão vegetal. Entretanto, os produtores demonstraram interesse em vender o segundo corte de sua plantação florestal para a indústria de celulose.

Caso não haja diferença de preço significativa entre a madeira para celulose e seus mercados concorrentes, acredita-se que no mínimo $50 \%$ dos produtores devem comercializar a madeira de segundo corte com a indústria de celulose. Esse valor contempla os $32 \%$ que venderão para a indústria de celulose, dependendo do preço da madeira, e os $18 \%$ que já disseram ter interesse em vender para a empresa. Foram desconsiderados produtores que não opinaram e os fomentados que apontaram mercados alternativos, como escoramento, cerâmica e carvão.

Encontrando opções mais atrativas, a maioria dos produtores se dispunha a vender sua madeira para outros fins, como: escoramento, lenha e carvão. Os interesses por outros mercados madeireiros estão contidos na Tabela 9.

O uso da madeira onde os produtores pretendem vender sua brotação (Tabela 9) representa seu interesse pelo mercado, mas não necessariamente onde será comercializado de fato, devido a oscilações de preços nesses mercados.

O carvão vegetal com $60 \%$ está em primeiro lugar como mercado alternativo para venda da madeira após o término do contrato de fomento florestal

A venda de madeira principalmente para construção civil (escoramento) ficou em segundo lugar (21\%) como mercado de interesse dos produtores fomentados e a venda para cerâmicas, em terceiro $(8 \%)$.

Na opinião dos produtores, os custos de transporte para os mercados apontados na Tabela 9 são menores, sendo para a indústria de celulose valores maiores.

Os produtores fomentados foram unânimes ao dizer que os custos de transporte chegavam a $50 \%$ do valor total da venda da madeira. Estratégias como redução dos custos de transporte terão significativo impacto no estímulo e vantagens do programa de fomento florestal.

Essa redução pode ser via organização de uma cooperativa de transporte florestal dos produtores fomentados, negociação com uma empresa de transporte para atendimento aos fomentados ou outras ações de caráter coletivo. A empresa pode também estabelecer pátios de recebimento de madeira mais próximos às áreas.

Tabela 9 - Mercados de interesse dos produtores para a venda futura da madeira após o término do contrato Table 9 -Markets that producers might consider for possible future wood sales after finishing the first contract

\begin{tabular}{|c|c|c|c|c|c|c|}
\hline \multirow[t]{2}{*}{ Item } & \multicolumn{2}{|c|}{ PFCA } & \multicolumn{2}{|c|}{ PFCF } & \multicolumn{2}{|c|}{ Média Geral } \\
\hline & No. & $\%$ & No. & $\%$ & No. & $\%$ \\
\hline Escoramento & 20 & 24 & 10 & 18 & 30 & 21 \\
\hline Carvão & 49 & 58 & 35 & 61 & 84 & 60 \\
\hline Cerâmicas & 8 & 9 & 4 & 7 & 12 & 8 \\
\hline Outros fins & 3 & 4 & 0 & 0 & 3 & 3 \\
\hline Não opinou & 4 & 5 & 8 & 14 & 12 & 8 \\
\hline Total & 84 & 100 & 57 & 100 & 141 & 100 \\
\hline
\end{tabular}

\section{CONCLUSÕES}

Os seguintes fatores contribuem para a confiança, confiabilidade e desconfiança entre produtores fomentados e empresa de base florestal:

- A confiabilidade no comportamento dos produtores em honrar o contrato de fomento florestal foi confirmada.
- A empresa fomentadora não apresentou estratégias para estímulo dos produtores a comercializarem o segundo corte com a indústria. Esse fator reduz a confiabilidade na compra da madeira via fomento.

- Dos fomentados entrevistados, $18 \%$ afirmaram que iriam vender, mesmo tendo outros mercados mais

R. Árvore, Viçosa-MG, v.33, n.4, p.723-732, 2009 
atrativos, a madeira do segundo ciclo para a empresa fomentadora. Acredita-se que não havendo oscilações grandes no mercado concorrente pela compra da madeira, aproximadamente $50 \%$ dos produtores venderiam para a indústria de celulose.

- A perspectiva de crescimento do setor florestal gera credibilidade para investimentos por parte dos produtores, gerando, assim, confiabilidade no mercado de madeira para produção de celulose.

- Os produtores almejam ganhos futuros com o programa de fomento, e, assim, variações ocasionais no curto prazo nos preços de produtos concorrentes não proporcionam quebra de contrato de uma grande maioria de produtores fomentados.

- Os produtores na sua grande maioria não entendem o atual sistema de medida da madeira.

- A determinação do preço da madeira de acordo com a distância gera insatisfações por parte dos produtores com propriedades próximas aos locais de entrega da madeira.

O custo de transporte para o produtor é o principal desmotivador para o investimento em plantação florestal para produção de celulose.

\section{AGRADECIMENTOS}

Ao Conselho Nacional de Desenvolvimento Científico e Tecnológico (CNPq), à Fundação de Amparo à Pesquisa de Minas Gerais (FAPEMIG), aos produtores rurais participantes da pesquisa e à Celulose NipoBrasileira (CENIBRA), pelo indispensável apoio.

\section{REFERÊNCIAS}

HARDIN, R. Conceptions and explanations of trust. In: COOK, K. S. Trust in society. New York: Russell Sage Foundation, 2001. p.403.

OLIVEIRA, P. R.; VALVERDE, S. R.; COELHO, F. M. G. Aspectos de relevância econômica no fomento florestal a partir da percepção dos produtores rurais envolvidos. Revista Arvore, v30, n.4, p.593-602, 2006.

PUTNAM, R. Making democracy work: civic traditions in modern Italy. Princeton: University Press, 1993. 280p.

SOARES, N. S. Potencial de implantação de um contrato futuro de madeira de reflorestamento. 2006. FOLHAS Dissertação (Mestrado em Ciência Florestal) - Universidade Federal de Viçosa, Viçosa, MG, 2006.

VALVERDE, S. R. et al. Efeitos multiplicadores da economia florestal brasileira. Revista Árvore, v.27, n.3, p.285-293, 2003.

WILliAMSON, O. The economic institutions of capitalism: firms, markets, relational contracting. London: Free Press, 1985. 450p.

ZYLBERSZTAJN, D. Papel dos contratos na coordenação agro-industrial: um olhar além dos mercados. Revista de Economia e Sociologia Rural, v.43, n.3, p.385-420, 2005. 